\title{
Tiempo y subjetividad en M. Merleau-Ponty
}

M. ${ }^{2}$ Carmen López Sáenz

Merleatt-Ponty estudia la experiencia vivida de la temporalidad, et movimiento de una conciencia situada en el mundo. La temporalidad originaria no se halla en el tiempo cartesiano: «El tiempo en sentido amplio, esto es, el orden de las coexistencias, tanto como el orden de las sucesiones, es un medio al que no se puede acceder más que ocupando en él una situación y captándolo por entero a través de los horizontes de esta situación» ${ }^{1}$. El tiempo no existe en las cosas, sino en las relaciones con las cosas; no es una suma de «ahoras» puntuales. Los instantes no pueden articularse para formar el tiempo, sino a través de ese ser ambigto que Merleau-Ponty llama «subjetividad», no pueden devenir co-presentes más que desde cierto punto de vista y para una intención. La esencia de las cosas y del mundo es su apertura, es decir, nos remiten más allá de sus manifestaciones determinadas. De ahí que, para MerleauPonty, el tiempo sea una especie de presente ek-stático, continuamente fuera de $s^{2}{ }^{2}$, un presente ambiguo. Temporalidad, sexualidad, espacialidad, etc., son dimensiones de la existencia.

Merleau-Ponty estudia el tiempo siguiendo su dialéctica interna para lograr así refundir su idea del sujeto.

El tiempo supone, como decíamos, un punto de vista sobre el tiempo. No es, pues, una corriente, una sustancia que fluye. Pensamos el tiempo antes que sus partes; las relaciones temporales posibilitan los acontecimientos en el tiempo. Este no es un dato de la conciencia, sino que es ella la que constituye el tiempo. Por la idealidad del tiempo, deja la

' Merleau-Ponty, M., Fenomenología de la percepción, p. 345.

2 "El tiempo es el medio ofrecido a todo lo que será para ser a fin de que no sea ya "más" ". Claudel, P., Art poétique, p. 57. 
conciencia de estar prisionera en el presente. Es esencial al tiempo el que nunca esté completamente constituido: «El tiempo constituido, la serie de las relaciones posibles según el antes y el después, no es el tiempo, es su registro final, es cl resultado de su paso, que el pensamiento objetivo siempre presupone y no consigue captar. Es espacio, ya que sus momentos coexisten ante el pensamiento, es presente porque la conciencia es contem. poránca de todos los tiempos. Es un medio distinto de mí e inmóvil, cl tiempo propio de un sujeto desencarnado. Merleau-Ponty evita la sintesis kantiana: no hay instantes separables, sino continuo deslizamiento de una temporalidad. El sentimiento de la experiencia de esta temporalidad no culmina en una síntesis de identificación, sino en una síntesis de transición, es decir, en la manera de vivir los acontecimientos tal y como surgen el uno del otro, teniendo en cuenta que cada uno sólo es un aspecto de la totalidad. El origen del tiempo no debe buscarse en una síntesis eterna, en una capacidad absoluta de salir de esta vida y contemplarla como un film. No hay lugar para reunir los momentos exteriores en la unidad de la subjetividad: puesto que no soy espectador de mi vida, no tengo que pensar su unidad, sino desplegar la totalidad de mi ser exteriorizándome; la cohesión de una vida viene dada con su ék-stasis; el paso del presente a otro presente no lo pienso, lo efectúo. Esto es el tiempo. No se trata de un objeto de nucstro saber, sino -como anunciábamos- de una dimensión de nuestro ser. Mi campo de presencia es la experiencia originaria en la que el tiempo y sus dimensiones se me aparecen sin distancia interpuesta. En él, vemos el futuro deslizándose en el presente y el pasado. El presente no está pro-puesto, no paso por una serie de ahoras, cuya imagen conservaría y que, empalmadas formarían una línea. En cada momento, el momento precedente se modifica. «El tiempo no es una línea, sino una red de intencionalidades» ${ }^{3}$. En la experiencia primordial que tenemos del tiempo, ćste no es para nosotros un sistema de puntos fijos a través de los cuales pasamos, sino un medio movedizo que se aleja de nosotros, como el árbol desde la ventanilla del tren. Sin embargo, no creemos en serio que el árbol se mueva. La percepción se presenta como indivisión espacio-temporal, porque "percepción» es la forma de dirigirse al mundo de un sujeto esencialmente comprometido. Ser y pasar son sinónimos. Al devenir pasado, el acontecimiento no deja de ser. El origen del tiempo objetivo se halla en la recuperación del pasado y del futuro en el presente, en el paso mismo del tiempo. En Merleau-Ponty, al igual que en Heidegger, la temporalización no es una sucesión de ék-stasis, es la vida del tiempo, la subjetividad. «Bergson se equivocaba al explicar la unidad del tiempo por su continuidad, pues ello equivale a confundir pasado,

Merleau-Pontr, Id., p. 425. 
presente y futuro [...] equivale, en definitiva, a negar el tiempo. Pero estaba en lo cierto al aferrarse a la continuidad del tiempo como a un fenómeno esencial» ${ }^{4}$. Pasado y futuro sólo aparecen cuando una subjeti. vidad rompe la plenitud del ser en sí e introduce el no-ser en su perspectiva. Las cosas sólo son pasadas o futuras en relación a un sujeto; no existe un pasado, presente o futuro en sí. «Se dice que hay un tiempo como se dice que hay un chorro de agua: el agua cambia y el chorro de agua permanece» ${ }^{5}$. Esto ocurre porque la forma se conserva; el permanecer del tiempo es su forma. "Hay que entender el tiempo como sujeto y el sujeto como tiempo" ${ }^{6}$. La temporalidad originaria es el poder que une los acontecimientos, alejándolos uno de otro. La subjetividad última, la conciencia última no es temporal porque si la conciencia del tiempo estuviese hecha de estados de conciencia sucesivos, sería necesaria una nueva conciencia para tomar conciencia de esta sucesión y así indefinidamente.

Merleau-Ponty privilegia el ék-stasis presente; en él hay un ék-stasis hacia el futuro y hacia el pasado que hace aparecer las dimensiones del tiempo como inseparables. El presente es el punto de partida; expresa la ambiguiedad inicial del tiempo: retener es tener, pero a distancia.

Lo único que en el tiempo no pasa es el paso del tiempo. El tiempo siempre se está recomenzando. Hay tiempo para mí porque estoy situado en él, porque tengo un presente. «Es al llegar al presente que un momento del tiempo adquiere la individualidad imborrable» ${ }^{\text {? }}$. El presente es privilegiado porque es la zona en la que el ser y la conciencia coinciden. Hace un momento deciamos que hay una conciencia última. Esta captaría su propio ser y su propia conciencia. Dicha conciencia del presente. Aquí la conciencia de existir se confunde con la existencia, con el ser-en-el-mundo.

Puesto que el Otro está presente en el mundo, en una realidad en la que yo también estoy presente, el Otro desarrolla una teroporalización que no es la mía. Dos temporalidades no se excluyen; pueden entrelazarse proyectándose en el presente. Del mismo modo que mi presente abre hacia el pasado y hacia el futuro, también puede abrir a unas temporali. dades, que yo no vivo, y tener un horizonte social, de modo que el mundo individual se amplíe en la historia colectiva. El presente preobjetivo, vivido, es mi corporeidad, nuestra sociabilidad, la preexistencia del mundo $y$, al mismo tiempo, el fundamento de nuestra libertad.

${ }^{4}$ Ib., p. 428.
s Ib., p. 429.
${ }^{6}$ Ib., p. 430.
I Ib., p. 431. 
Los hombres no somos los autores del tiempo; nosotros no decidimos nacer, pero, una vez en el mundo, el tiempo transcurre a través de mí. Este aparecer del tiempo no es simplemente soportado por mí. No somos receptores pasivos del tiempo, sino que «es un investir, un ser en situa. ción, ante ei cual no existimos, que perpetuamente recomenzamos y que es constitutivo de nosotros mismos" ${ }^{8}$. Adquirimos la espontaneidad, el tiempo y la subjetividad de una vez por todas.

Merleau-Ponty se opone al tiempo histórico de Heidegger qute fluye del futuro y experimenta la unidad en la dispersión. Nuestro centro es el presente, de aquí parten nuestras decisiones, y nosotros somos el surgir del tiempo.

El mundo es inseparable del sujeto, pero de un sujeto que es proyecto dcl mundo. El sujeto es ser-del-mundo y el mundo es «subjetivo», puesto que sus relaciones son establecidas por el movimiento trascendente del sujeto.

El análisis merleau-pontyniano del tiempo profundiza en esta idea porque subraya al sujeto y al objeto como dos momentos abstractos de una estructura única que es la presencia. Gracias al tiempo pensamos el ser. Nuestro saber del tiempo es una dialéctica exenta de síntesis (el presente como dialéctica entre pasado y futuro), abierta, existencial, no reductiva $(. .$.$) un reflejo de la dialéctica viviente de la praxis humana.$

Ib., p. 435 . 